\title{
Prevalence and risk factors of Leptospira infection in urban brown rats (Rattus norvegicus), Vienna, Austria
}

\author{
Amélie Desvars-Larrive ${ }^{1,2,3}$ (D) Steve Smith ${ }^{4}$ (D) $\cdot$ Gopi Munimanda ${ }^{4} \cdot$ Pascale Bourhy $^{5}$ (D) Theresa Waigner ${ }^{3}$. \\ Margaret Odom $^{6}$ • Diana S. Gliga ${ }^{3}$ (D) Chris Walzer $^{3,7}$ (D)
}

Published online: 3 March 2020

(C) The Author(s) 2020

\begin{abstract}
Leptospirosis is a worldwide bacterial zoonosis which incidence is expected to increase in conjunction with global change. In urban ecosystems, synanthropic rats are the key source of Leptospira infection in humans and other animals. Risk assessment and prediction of human leptospirosis require investigations of the environment associated with the bacteria and infection patterns in the reservoir hosts. The objective of this study was to address the prevalence of mixed Leptospira infection in the lungs and kidneys of brown rats captured in three sites of the city centre of Vienna, Austria, between 2016 and 2018. A total of 96 brown rats were examined for the presence of Leptospira using PCR. Occurrence of mixed Leptospira infections was explored through next-generation sequencing (NGS). A logistic regression model was built to predict the individual infection status using morphological and land-use data. Overall, the prevalence of Leptospira interrogans in the kidney was $25 \%$ but varied among sites $(0-$ $36 \%$ ). We did not evidence any pulmonary nor mixed infections. Host body mass and sex were strong predictors of Leptospira carriage in the sampled rats (relative variable importance $(\mathrm{RVI})=0.98$ and 0.89 , respectively) while the presence of water affected it moderately $(\mathrm{RVI}=0.44)$. Our findings demonstrate that NGS is an unbiased approach to the direct characterisation of mixed leptospiral infections that could provide further insights into the ecology of Leptospira. Future surveillance programmes should consider the use of rats as sentinels for the early detection of emerging pathogenic Leptospira in urban ecosystems.
\end{abstract}

Keywords Rattus norvegicus · Urban · City · Leptospira interrogans · Sentinel $\cdot$ Zoonosis

Electronic supplementary material The online version of this article (https://doi.org/10.1007/s11252-020-00957-9) contains supplementary material, which is available to authorized users.

Amélie Desvars-Larrive

amelie.desvars@vetmeduni.ac.at

1 Unit of Veterinary Public Health and Epidemiology, University of Veterinary Medicine, Vienna, Austria

2 Complexity Science Hub, Vienna, Austria

3 Research Institute of Wildlife Ecology, University of Veterinary Medicine, Vienna, Austria

4 Konrad Lorenz Institute for Ethology, University of Veterinary Medicine, Vienna, Austria

5 Institut Pasteur, Biology of Spirochetes Unit, National Reference Center for Leptospirosis, Paris, France

6 Cornell University, Ithaca, NY, USA

7 Wildlife Conservation Society, Wildlife Health Program, Bronx, NY, USA

\section{Introduction}

Data on global trends in urbanization indicates that by 2050 the global population will be $68 \%$ urban, with the number of urban dwellers reaching 6.7 billion (United Nations Department of Economic and Social Affairs Population Division 2019). Urbanisation creates critical wildlife-human-environment interfaces which are considered hot-spots for cross-species transmission and emergence of novel pathogens (Dixon et al. 2014; Hassell et al. 2017). Knowledge on the epidemiology of urban wildlife diseases is essential as it has direct implications in preventing and controlling the spread of zoonoses in humans and domestic animals in cities (Hassell et al. 2017; Mackenstedt et al. 2015). The brown (or Norway) rat, Rattus norvegicus (Berkenhout, 1769), has colonised all continents except Antarctica (Feng and Himsworth 2014). It is very prolific in urban and sub-urban ecosystems and is a successful urban exploiter (McKinney 2006). Rats have long been considered pests. Beside the damage they cause to urban infrastructures and foodstuff (Battersby et al. 2008), they indirectly impact the mental health of urbanites (Byers et al. 2019; Zahner et al. 1985) while 
directly threating their physical health with the diverse zoonotic pathogens they harbour (Himsworth et al. 2013b; Strand and Lundkvist 2019). Leptospirosis is the most widespread ratborne disease (Evangelista and Coburn 2010). It is caused by a spirochaetal bacterium of the genus Leptospira that includes 35 recognized species, of which 13 are pathogenic for humans and animals (i.e. causing disease) and 11 are intermediate species, inducing variable and mild symptoms (Thibeaux et al. 2018). In addition, 30 novel species have been described from water and soil samples, which highlights the great biodiversity of the genus and the capacity of these bacteria to survive in the environment (Vincent et al. 2019). Wild rats (Rattus spp.) are chronic asymptomatic carriers of Leptospira spp., maintaining the spirochetes in their proximal renal tubules, and are viewed as the key source of infection to humans, particularly in urban habitats (Boey et al. 2019).

Human infection occurs through direct contact with the urine of an infected animal or, indirectly, via contact with water or soil contaminated with leptospires. The bacteria can enter the body though a cut or abrasion in the skin or through the mucous membranes (Haake and Levett 2015). The disease has a significant health impact, affecting an estimated 1.03 million humans annually worldwide and causing 58,900 deaths (Costa et al. 2015).

Prevalence is highest in tropical regions where leptospirosis mainly affects the most vulnerable, lower-income, populations (Costa et al. 2015). However, the risk of leptospirosis transmission in cities of the developed and industrialized countries, as defined in (United Nations 2016), is now recognized as of increasing importance (Boey et al. 2019). This risk has been demonstrated in Baltimore, USA (Vinetz et al. 1996), Tokyo, Japan (Koizumi et al. 2009), Marseille, France (Socolovschi et al. 2011), and Palermo, Italy. Yet, data on the prevalence of Leptospira infection in city rats in industrialized countries remains scarce.

In this study, we aimed to i) address the prevalence of Leptospira infection in the lung and kidney tissues of urban brown rats captured in three sites of the city centre of Vienna, Austria, that are highly frequented by humans, ii) identify the Leptospira species involved, and iii) characterize mixed Leptospira infections through an original and unbiased approach involving next-generation sequencing (NGS).

\section{Materials and methods}

\section{Study areas and sampling methods}

Rattus norvegicus were trapped between 12 September 2016 and 13 November 2018 in three sites highly frequented by humans in the city centre of Vienna, Austria: i) at a promenade along the Danube canal (mean coordinates of the trapped rats: 16.36540, 48.22633 decimal degrees (D.D.)), ii) at Karlsplatz
(16.36305, 48.20027 D.D.), one of the tourist attractions in the city, and iii) at Schwedenplatz (16.37531, 48.21228 D.D.), a cruise port on the Danube river. These sites were used for trapping as rats could be observed during daytime, suggesting that the rats were abundant and that these locations may represent critical interfaces for Leptospira transmission between rats, humans, companion animals (dogs), and the environment (Hassell et al. 2017).

Rats were captured alive using Manufrance live-traps ( $280 \times$ $100 \times 100 \mathrm{~mm}$ ). Traps were set between 17.00 and 19.30, and retrieved the following morning between 6.00 and 8.00. The trapping effort per site (\# traps set $\mathrm{x}$ \# nights) was adjusted according to the method described by Nelson and Clark (1973). Captured animals were transferred alive to the pathology laboratory where they were anesthetised using 5\% isoflurane before euthanasia via an intra-peritoneal barbiturate overdose. Rats were identified to species based on morphological characters. For each animal, the following data were recorded: sex, body mass (g), body length (nose to anus, $\mathrm{mm}$ ), cutaneous wound score, and sexual maturity. Presence of cutaneous wounds was scored into five categories based on Glass et al. (1988), i.e. unwounded animals: score 0; minor tail wounds: score 1; large wounds on the tail and small wounds on the rump, base of the tail or limbs: score 2; larger wounds on the body: score 3; more extensive wounds: score 4. Males were considered sexually mature if they had scrotal (vs. inguinal) testes and developed seminal vesicles. Females were considered mature if their uterus showed distinct blood supply, placental scars, or presence of embryos as defined in (Vadell et al. 2010). During necropsy, lung and kidney tissues were collected aseptically. A ten $\mathrm{mm}$ tail tip was sampled for barcoding purpose. All samples were maintained at $-80^{\circ} \mathrm{C}$ until DNA extraction.

Maps of the capture sites were built using QGIS 3.4.5 (QGIS Development Team, 2018); the raster data "Orthofoto 2016 Wien” (Open Data Österreich, https://www.data.gv.at/) was used as base map.

\section{Mitochondrial DNA sequence generation and analyses}

DNA barcoding was used to confirm the morphological identification of the Rattus species. DNA was extracted using a modified salting-out method (Sunnucks and Hales 1996). In brief, tissue was digested with $15 \mu \mathrm{l}$ proteinase $\mathrm{K}(10 \mathrm{mg} / \mathrm{ml})$ buffered in $500 \mu \mathrm{l}$ TNES solution $(400 \mathrm{mM} \mathrm{NaCl}, 50 \mathrm{mM}$ Tris $\mathrm{pH} 7.5,0.5 \%$ SDS, $20 \mathrm{mM}$ EDTA) and centrifuged $20 \mathrm{~min}$ at $12,000 \mathrm{rpm}$ at room temperature. Then, DNA was precipitated from the supernatant with $500 \mu \mathrm{l}$ of isopropanol before being pelleted and washed twice with $70 \%$ ethanol. The resulting pellet was resuspended in $100 \mu \mathrm{l}$ of $0.1 \mathrm{x}$ Tris EDTA buffer.

We amplified a 585-bp fragment of the mitochondrial DNA (mtDNA) D-loop using the primers EGL4L (5'-CCAC CATCAACACCCAAAG-3') and RJ3R (5'-CATG 
CCTTGACGGCTATGTTG-3') as described in (Robins et al. 2007). Amplicons were Sanger sequenced on an ABI3130xl capillary electrophoresis analyser (Applied Biosystems). Sequences were aligned using BioEdit (Hall 1999) and compared through Blast-based analysis against the National Center for Biotechnology Information (NCBI) nucleotide collection database (NCBI Resource Coordinators 2017).

\section{Molecular detection of Leptospira spp.}

DNA was extracted from kidney and lung tissues $(25 \mathrm{mg}$ ) using the DNeasy® Blood \& Tissue kit (Qiagen, Hilden, Germany) in accordance with the manufacturer's instructions. Quality and concentration of DNA extracts were estimated via spectrophotometry using a NanoDrop 1000 instrument (Thermo Fisher Scientific, Waltham, Massachusetts). Sample concentrations were then normalised to $15 \mathrm{ng} / \mu \mathrm{l}$ prior to amplification. The DNA was stored at $-20{ }^{\circ} \mathrm{C}$ until used. Each sample was screened by PCR targeting the $16 \mathrm{~S}$ rRNA gene using the primer pair LeptoA $\left(5^{\prime}\right.$-GGCGGCGCGTCTTA AACATG-3') and LeptoB (5' -TTCCCCCCATTGAG CAAGATT-3'), under standard conditions (Mérien et al. 1992). To confirm the results, a second PCR was conducted using primer pair LeptoC (5'-CAAGTCAAGCGGAG TAGCAA-3') and LeptoD (5'-CTTAACCTGCTGCC TCCCGTA-3'), under standard conditions (Mérien et al. 1992). The amplification products were visualized by electrophoresis on a $2 \%$ agarose gel stained with GelRed® Nucleic Acid Gel Stain (Biotium, Fremont, California). As positive controls, we used DNA from Leptospira interrogans strain RGA, Leptospira licerasiae strain Var010, and Leptospira biflexa strain Patoc (Pasteur Institute, Paris, France).

\section{NGS library preparation}

Two positive samples were initially subject to Sanger sequencing on an ABI3130xl (Applied Biosystems, California) to confirm amplification of the target region. To characterize mixed Leptospira infections, NGS analysis was performed on each positive sample. Each positive amplicon was subjected to a second round of PCR to attach a 5'overhang nucleotide sequence containing a unique index tag and adaptors compatible with Illumina MiSeq PE 150 nano chemisty (Illumina, San Diego, California). The reaction mix consisted of 1 x PCR AmpliTaq Gold Buffer, 1.25 unit AmpliTaq Gold® DNA Polymerase (Life Technologies, Eugene, Oregon), $1.5 \mathrm{mmol} / 1 \mathrm{MgCl}_{2}, 0.2 \mathrm{mmol} / 1$ dNTPs, $0.2 \mathrm{mmol} / \mathrm{l}$ tagged primer pair, $50 \mathrm{ng}$ DNA extract, and ultrapure water (Invitrogen) to a final volume of $25 \mu \mathrm{l}$. The amplification protocol consisted of an initial denaturation at $95{ }^{\circ} \mathrm{C}$ for $3 \mathrm{~min}$ followed by 15 cycles of denaturation at $98^{\circ} \mathrm{C}$ for $20 \mathrm{~s}$, primer annealing at $56^{\circ} \mathrm{C}$ for $30 \mathrm{~s}$, and DNA extension at $72{ }^{\circ} \mathrm{C}$ for $45 \mathrm{~s}$ before the final extension step at $72{ }^{\circ} \mathrm{C}$ for $5 \mathrm{~min}$.
The barcoded amplicons were purified as described in (Rohland and Reich 2012). The amplicon concentrations were estimated using Qubit ds DNA BR Assay Kit (Life Technologies, Eugene, Oregon) in accordance with manufacturer's instructions. The tag-indexed PCR products were pooled in equimolar concentrations and underwent $150 \mathrm{bp}$ pair-end sequencing on an Illumina MiSeq PE 150 system (Illumina, San Diego, California) at the Vienna Biocenter Core Facility (Vienna, Austria).

Sequencing data was first de-multiplexed and adaptors removed before quality filtering of reads. All reads were run through a custom bioinformatics pipeline based on strain identification from the USEARCH program (Edgar 2010). Briefly, the pipeline discards reads that are sequencing artefacts (including chimeras) and then groups the remainder into operational taxonomic units (OTUs) which are analogous to strains of Leptospira. Due to lack of overlap in the paired-end reads each read was analysed separately and then combined for species annotation through Blast-based analysis against the NCBI nucleotide collection database (NCBI Resource Coordinators 2017).

\section{Land-use data}

To determine urban environmental features that could affect Leptospira occurrence in rats we extracted land-use data from the Vienna land-use dataset (Realnutzungskartierung ab 2007/ 08 Wien) (Bundesministerium für Digitalisierung und Wirtschaftsstandort 2019) using the software QGIS 3.4.5 (QGIS Development Team, 2018). This database contains three levels of land-use classification with 32 land-use classes. First, we approximated the home range of each captured rat by constructing a 200 m-radius (Gardner-Santana et al. 2009; Heiberg et al. 2012) circular buffer zone around each point of capture. Using the Intersection and the Add Geometry Attributes tools, we extracted for each buffer zone (i.e. approximated home range for each captured rat) the surface area covered by four major land-use categories, i.e. green, blue (water), building, and transport infrastructures.

\section{Statistical analysis and mapping}

Statistical analyses were conducted using R 3.5.1 (R Development Core Team, Vienna, Austria) and the level of significance was set to 0.05 .

We analysed the spatial autocorrelation between Leptospira-positive rats using the non-parametric spatial covariance function (Bjørnstad 2018) as implemented in the function spline.correlogram() in the $n c f$ library (Bjørnstad 2009). We used 9999 bootstrap resamples to generate $95 \%$ confidence intervals for the covariance function.

We investigated the effects of the place of capture, body mass, body length, sex, wound score, sexual maturity, and 
land-use variables on the individual infection status of rats (Leptospira-positive or -negative). Each land-use variable can be expressed as a combination of the three other ones. Therefore, because the surface covered by building infrastructure was the most important one (38\% of the total buffer surface area), this land-use variable was removed from the model. We computed a logistic regression model (generalised linear mixed-effect model under a binomial distribution) using the glmer function in the lme4 library (Bates et al. 2015) while controlling for clustering by site of capture (random effect). Model ranking and averaging were performed using the MuMIn library (Barton 2019). We calculated the conditional model average estimates, weighted according to the Akaike Information Criterion corrected for small sample size, AICc (Burnham and Anderson 2002). For each covariate, the relative variable importance (RVI) was computed from model averaged parameter estimate weights to determine the probability of each variable to contribute to the model for these data (Burnham and Anderson 2002).

\section{Results}

\section{Trapping}

Traps were set on 27 nights (Danube canal: 11, Karlsplatz: 14 nights, Schwedenplatz: 2). The adjusted trapping effort was 347 at Danube Canal, 408 trap-nights at Karlsplatz, and 74 at Schwedenplatz. Overall, $96 R$. norvegicus were captured (Danube canal: 44; Karlsplatz: 45; Schwedenplatz: 7)
(Figs. 1, 2, 3). The generated barcode sequences confirmed the morphological identification. Among the captured rats, 50 (52.1\%) were males (Danube canal: 24; Karlsplatz: 23; Schwedenplatz: 3 ) and 40 (41.7\%) were sexually mature (of which 22 were male and 18 were female). The median body mass and length (nose tip to anus) were $157.9 \mathrm{~g}$ and $188 \mathrm{~mm}$ for rats caught at Danube Canal, $134.2 \mathrm{~g}$ and $180.1 \mathrm{~mm}$ at Karlsplatz, $58 \mathrm{~g}$ and $135 \mathrm{~mm}$ at Schwedenplatz. Overall, the median body mass of sexually mature rats was $280.8 \mathrm{~g}$ versus $68.20 \mathrm{~g}$ for immature (Supplementary Material Fig. S1). Forty-two rats showed cutaneous wounds (18 rats were scored 1,14 were scored 2, five were scored 3, and five were scored 4) (Supplementary Material Table S1).

\section{Prevalence of Leptospira carriage}

PCR analysis revealed Leptospira spp. in the kidney tissue of 24 (25\%) rats, Karlsplatz: 8/45 (17.8\%), Danube canal: 16/44 (36.4\%), Schwedenplatz: 0/7. All lung tissues were negative. The median body mass of Leptospira-positive animals was $279.4 \mathrm{~g}$ versus $92.8 \mathrm{~g}$ for negative individuals. Fifteen (62.5\%) Leptospira-positive rats were females (median body mass $=294.4 \mathrm{~g}$ ) and nine were males (median body mass = 277.9 g) (Fig. 4). Sixteen (66.6\%) Leptospira-positive rats were sexually mature individuals (of which 11 were females). Among the Leptospira-positive rats, nine (37.5\%) individuals showed a cutaneous wound score of 0 , five $(20.8 \%)$ were scored 1 , seven $(29.2 \%)$ were scored 2 , one $(4.2 \%)$ was scored 3 , and two $(8.3 \%)$ were scored 4.

Fig. 1 Spatial distribution of the captured brown rats

( $R$. norvegicus) at Danube canal, September 12, 2016 - 13

November 2018, Vienna, Austria. Leptospira-positive animals are labelled

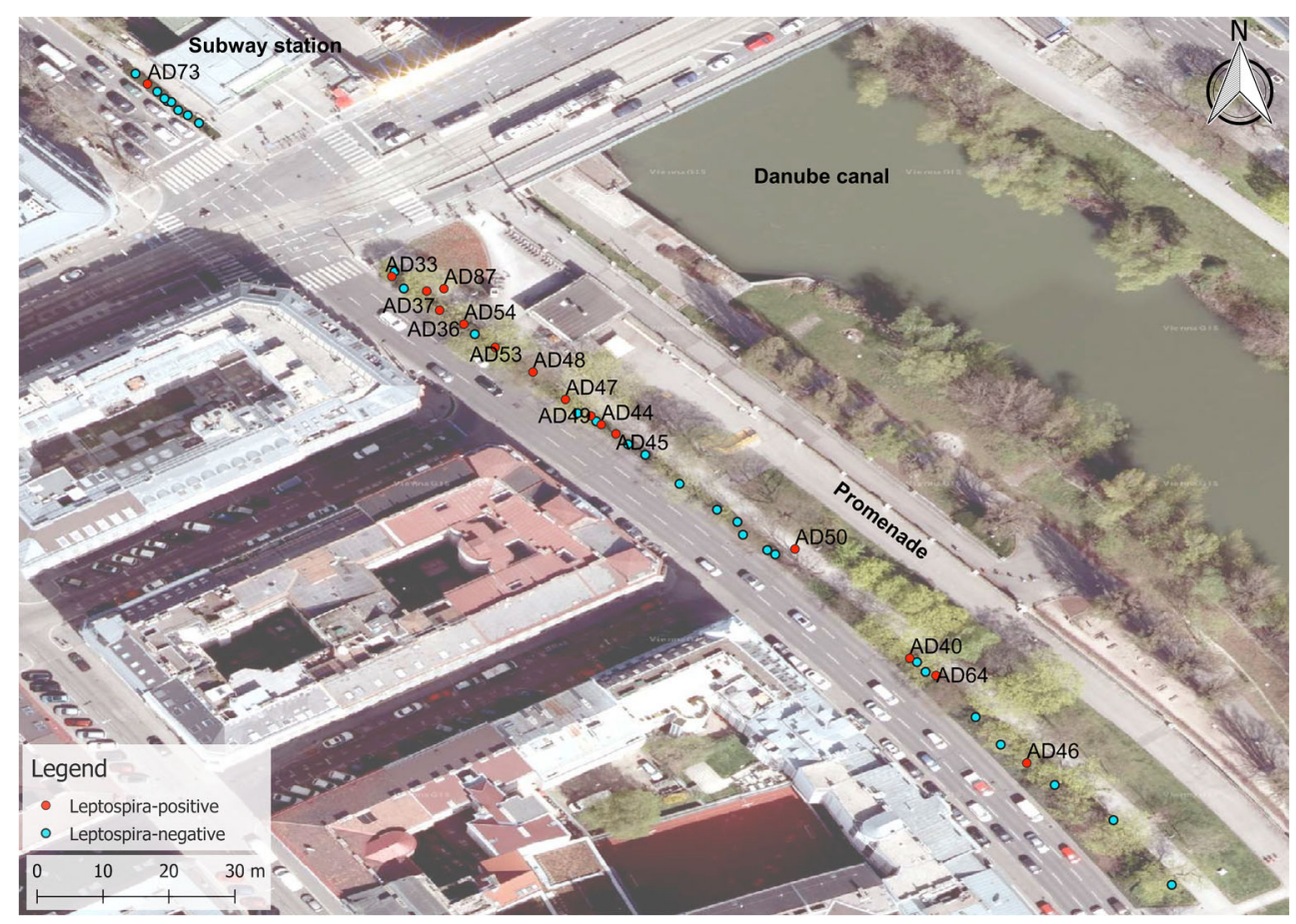


Fig. 2 Spatial distribution of the captured brown rats

(R. norvegicus) at Karlsplatz,

September 12, 2016 - 13

November 2018, Vienna, Austria.

Leptospira-positive animals are labelled

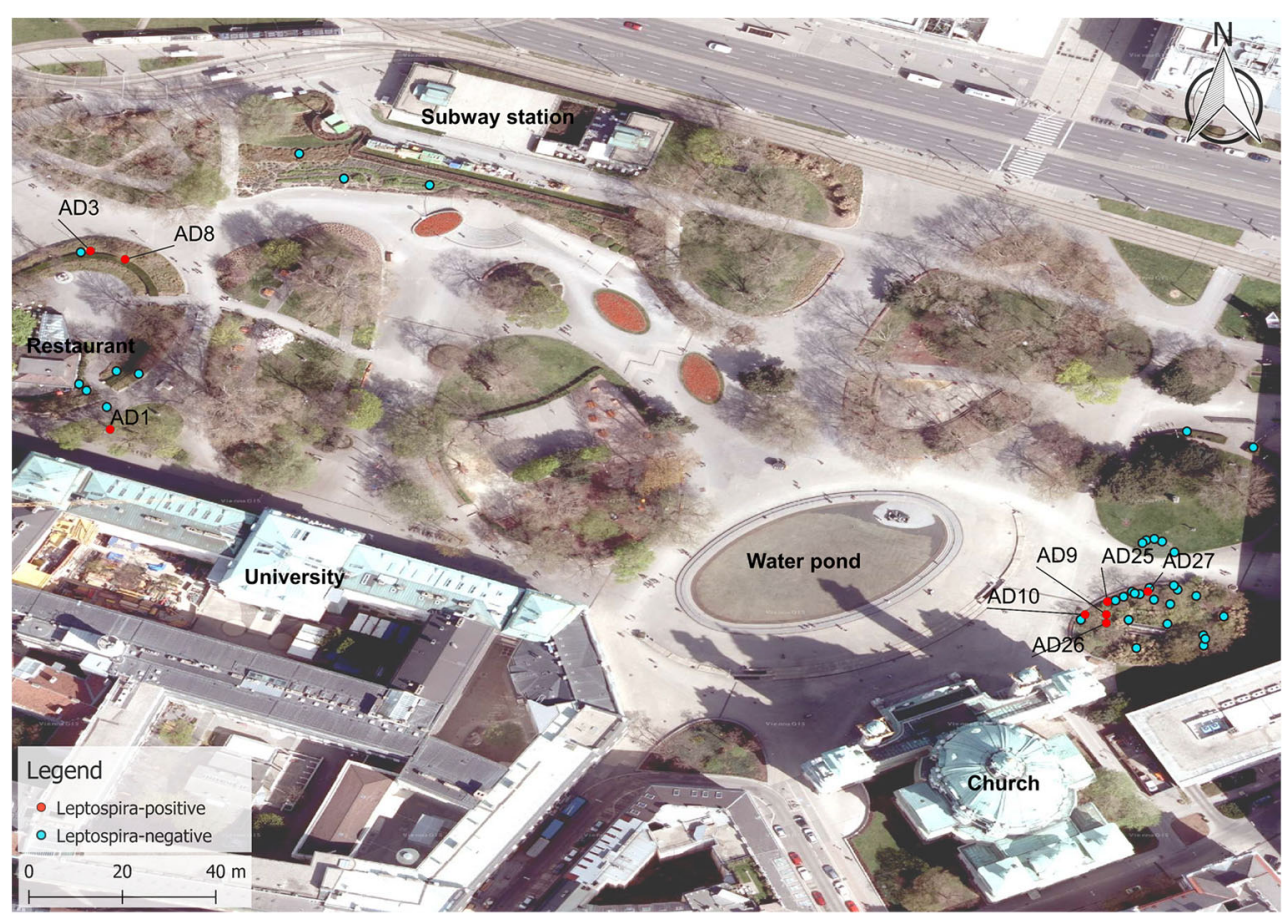

\section{Identification of Leptospira species}

The NGS workflow produced 1,730,882 raw sequence reads (mean number per sample $=50,908$; $\min =18,248$; $\max =$ 173,094). After primary data processing and discarding of spurious off-target sequences, a total of 1,229,857 reads remained as quality-filtered sequences (mean per sample $=36,172$; $\min =$ 1396; max. $=58,914)$. When combined, 614,888 of these paired reads could be assigned to the $5^{\prime}$ and $3^{\prime}$ ends of documented leptospiral 16S rRNA sequences (mean per sample $=18,085$; $\min =629 ; \max =29,228$ ). Blast-based analysis identified all reads as a single variant of $L$. interrogans. No mixed infection was detected. Additionally, two PCR positive samples not included in the NGS workflow were separately Sanger sequenced and returned Blast hits for the same Leptospira interrogans variant.
Fig. 3 Spatial distribution of the captured brown rats

(R. norvegicus) at Schwedenplatz, September 12, 2016 - 13

November 2018, Vienna, Austria

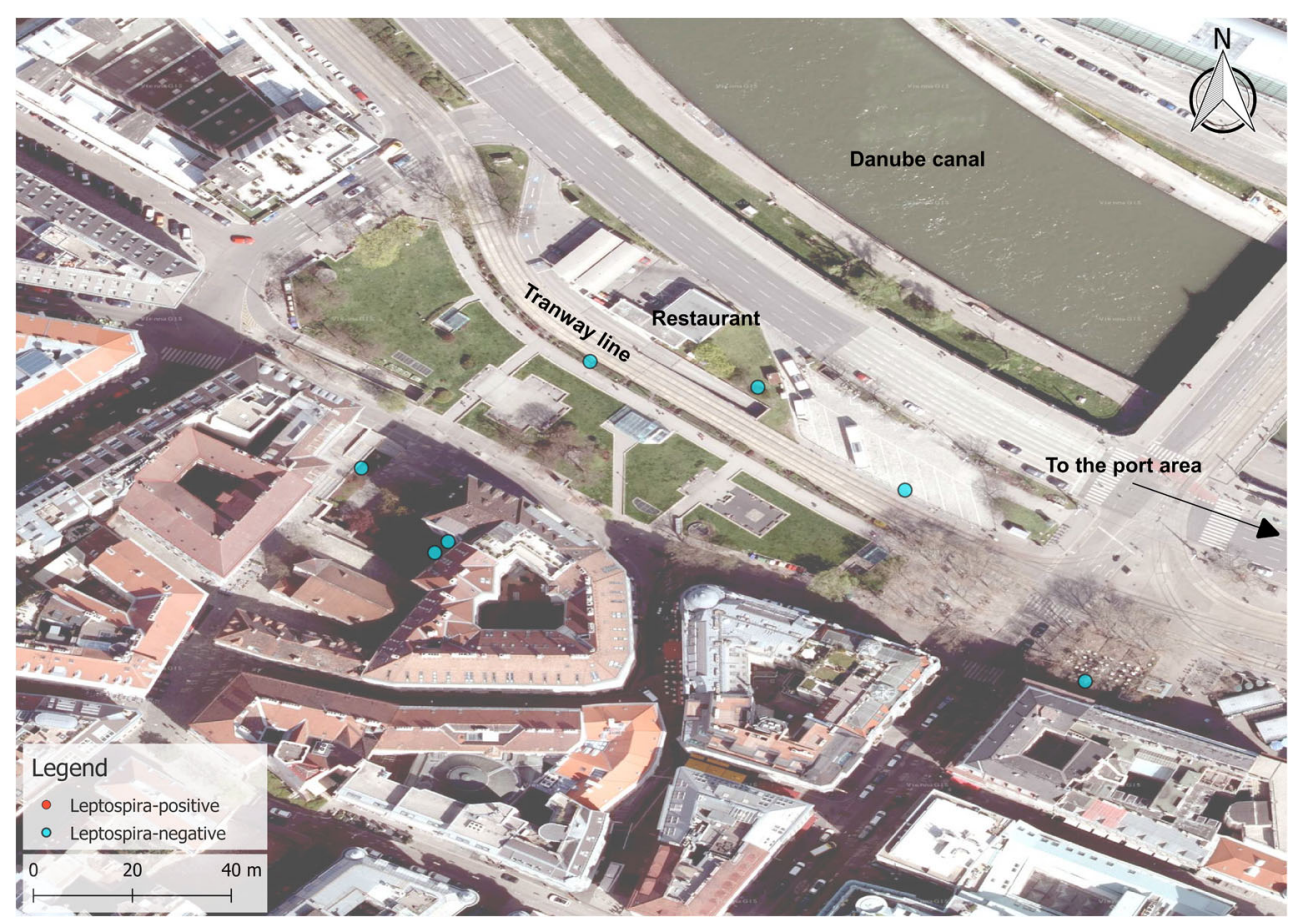


Fig. 4 Body mass of Leptospirapositive and -negative rats ( $R$. norvegicus) by sex and site, Vienna, Austria, 12 September 2016 - 13 November 2018

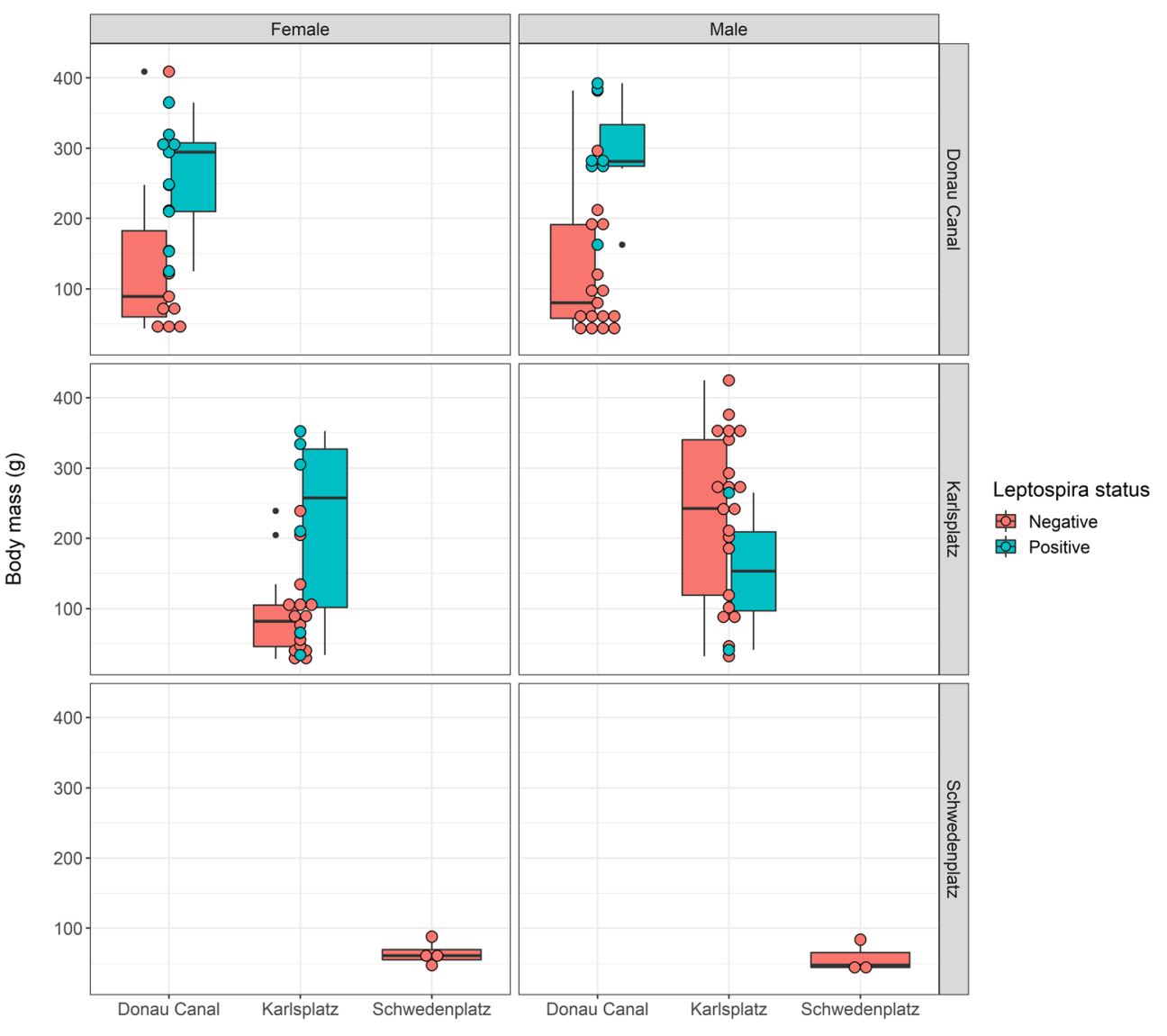

\section{Land-use}

Land-use coverage for each individual home range area is given in Supplementary Material Table S1. A summary of the surface occupied by each land-use category in the total home range of the captured rats for each investigated site is provided in Table 1.

\section{Determinants of Leptospira infection in urban rats}

The non-parametric spatial correlation did not reveal spatial autocorrelation between Leptospira-positive rats (Supplementary Material Fig. S2). Body length and mass were highly correlated (Spearman's rho $=0.96, p<0.001$ ), therefore, body length was excluded from the model. Statistical analysis revealed that host body mass and sex were strong predictors of Leptospira carriage in urban brown rats (RVI $=0.98$ and 0.89 , respectively). An increase in body mass was significantly associated with a higher risk of Leptospira carriage $(p<0.01)$ while females were significantly more at risk of Leptospira infection $(p<0.05)$. The presence of blue infrastructure (water) in the rat home range was the most important land-use variable to affect Leptospira carriage in urban rats, although this impact was moderate $(\mathrm{RVI}=0.44)$. Sexual maturity, wound score, presence of transport or green infrastructures showed a negligible impact on the carriage of Leptospira in the sampled rats (Table 2).

Table 1 Average percentage of each land-use category within the rat home range (based on a $200 \mathrm{~m}$-radius buffer surface around each capture point) at the three investigated sites, Vienna, Austria, 12 September 2016-13 November 2018.

\begin{tabular}{|c|c|c|c|c|}
\hline Capture site & Building & Transport & Blue infrastructure & Green infrastructure \\
\hline Danube canal & 35.7 & 34.4 & 16.8 & 13.1 \\
\hline Karlsplatz & 40.9 & 33.0 & 0.7 & 25.3 \\
\hline Schwedenplatz & 37.5 & 52.4 & 10.1 & 0 \\
\hline
\end{tabular}


Table 2 Model averaged parameter estimates (conditional average), adjusted standard errors (SE), and $p$ values of the generalised linear mixed-effect model of Leptospira carriage with binomial distribution and logit link function.

\begin{tabular}{lccc}
\hline & Model average estimates (adjusted SE) & p value & RVI \\
\hline Intercept & $-2.24(2.24)$ & 0.316 & \\
Body mass & $4.47(1.50)$ & 0.003 & 0.98 \\
Sex & & & 0.89 \\
Male & $-1.46(0.62)$ & 0.019 & \\
Sexual maturity & & & 0.30 \\
Mature & $-0.50(1.00)$ & 0.615 & \\
Wound score & $-0.12(0.30)$ & 0.705 & 0.27 \\
Blue infrastructure & $5.79(4.71)$ & 0.220 & 0.44 \\
Green infrastructure & $-2.69(7.21)$ & 0.710 & 0.30 \\
Transport infrastructure & $-3.04(7.98)$ & 0.703 & 0.27 \\
\hline
\end{tabular}

\section{Discussion}

We present molecular evidence that $25 \%$ of rats captured at three sites highly frequented by humans in the city centre of Vienna, Austria, are renal carriers of pathogenic L. interrogans. Although Leptospira can colonise the bronchial epithelium of naturally-infected wild brown rats (Zilber et al. 2016), we did not identify any pulmonary infection in the sampled rats. Moreover, although mixed pathogenic Leptospira infection was described in 2/18 R. norvegicus in Madagascar (Moseley et al. 2018), our study revealed only single-species infections.

Heavier rats (i.e. older rats) and females were more at risk of being renal carrier of Leptospira. Increased risk of leptospirosis in females has been seldom reported, although Easterbrook et al. (2007), Costa et al. (2014), and Minter et al. (2017) also described females at a higher risk of infection than males, but only in early life (Minter et al. 2017). The authors advanced behavioural or physiological difference that may expose females more than males to the bacteria (Minter et al. 2017).

Our findings confirmed that, at the city-scale, the prevalence of Leptospira carriage is heterogeneous (Himsworth et al. 2013a; Krojgaard et al. 2009; Minter et al. 2019) and influenced by the microhabitat, as also demonstrated in (Yusof et al. 2019). Our findings highlight that some urban sites, particularly those presenting blue infrastructures (e.g. water stream), could be areas of higher Leptospira transmission risk. This result is consistent with other studies demonstrating that river banks and soils (Thibeaux et al. 2017) but also muddy and flood risk zones (Goarant 2016) constitute highly favourable environments for the persistence and transmission of the bacterium.

While most screening approaches for Leptospira prevalence in hosts only consider single infections, we chose a NGS approach to uncover potential mixed infection. To the best of our knowledge, NGS has been used for detection of multiple Leptospira species on environmental samples only
(Sato et al. 2019). Another approach to investigating mixed infections in animal hosts involves the implementation of a multiplex PCR targeting multiple Leptospira species, followed by sequencing of the amplicons. However, this protocol only enables the detection of a limited number of species (Moseley et al. 2018). Our targeted NGS method, utilising universal Leptospira PCR primers in the first step, is an unbiased approach to the direct characterisation of leptospiral infections in tissue samples. This approach enables the identification of expected as well as unexpected Leptospira species and even the discovery of novel species. Our approach included a single sequencing run on a pooled library of positive Leptospira PCR products which is a cost-effective and timesaving method for the detection of mixed Leptospira infection. Determining if reservoir hosts can carry multiple Leptospira species gives further insights into the ecology of the bacterium.

Incidence of human leptospirosis is low in Austria (European Centre for Disease Prevention and Control 2014). However, a survey among adult male Austrians conducted in 2009 indicated an increasing exposure to Leptospira spp. during the past decade (Poeppl et al. 2013). More generally, the incidence of human cases of leptospirosis is rising in Europe (European Centre for Disease Prevention and Control 2018) as well as the rate of (peri-) urban transmission (Dupouey et al. 2014). The increase of the leptospirosis burden in European countries is most likely exacerbated by climate change (global warming and increased frequency and severity of extreme weather events) (Lau 2010), human population growth (Lau 2010), increasing urbanisation (Minter et al. 2018), increasing expansion of urban rodents (Boey et al. 2019; Dupouey et al. 2014; Vitale et al. 2018) and other wildlife reservoirs (Baldi et al. 2019; Jansen et al. 2007), and rise in international travels (Pijnacker et al. 2017). Rat population control through culling appears inefficient for reducing the risk of Leptospira transmission to humans (Lee et al. 2018). In consequence, control measures aiming at diminishing the incidence of urban leptospirosis must be expanded to incorporate ecological measures 
within an integrated pest-management programme (Centers for Disease Control and Prevention 2006).

The principal limitations of our study reside in the low sample size $(n=96)$ and number of sites investigated $(n=3)$. A greater sample size would have increased the power of the statistical analysis, hence providing a more detailed picture of the epizootiology of leptospirosis in urban rats. A greater number of sites would have provided a finer-scale evaluation of the spatial variability and environmental risk factors of leptospirosis in the city. To better estimate the risk for public health, seasonality in the prevalence of the renal carriage within the rat population should be explored. Furthermore, integration of data from human patients and other reservoir compartments, i.e. wildlife, domestic animals, and the environment, would have given a better insight into the epidemiological situation and potential routes of transmission of Leptospira in the city. In addition, an in-depth investigation of the renal microbiome of urban wild rats through NGS analysis would help understanding the within-host dynamics of Leptospira infections (i.e. single, mixed infection, or absence of infection).

\section{Conclusion}

Our study suggests that characteristics of the reservoir hosts (i.e. sex and body mass) and of the microenvironment (i.e. presence of water) could be used as predictors of the prevalence of leptospirosis in urban rats. These results can help public health authorities to assess spatial variations in the risk related to the presence of rats in the city. Because rats are ubiquitous in urban settings, have a small home range (Feng and Himsworth 2014), and because monitoring Leptospira infection in hosts is achievable on carcasses that can be provided by pest management professionals (Strand et al. 2015), brown rats can be used as early spatial predictors of human leptospirosis cases in cities (Pellizzaro et al. 2019) but also as sentinels for the early detection of emerging pathogenic Leptospira in urban ecosystems. The implementation of a surveillance programme through a One Health approach that monitors the Leptospira status of the wildlife reservoir, surveys the bacterial load in the environment, and identifies the circulating Leptospira species using an automated workflow is of high interest to urban health. This is particularly true in developed urban areas where leptospirosis is not yet endemic but may demonstrate, in a near future, an increase in prevalence driven by anthropogenic global change.

Acknowledgements We thank Felix Knauer for his support with statistics.

Funding statement ADL was financially supported by a postdoctoral fellowship (FU-282-PDC) provided by the University of Veterinary Medicine Vienna, Austria.
Funding Information Open access funding provided by University of Veterinary Medicine Vienna.

\section{Compliance with ethical standards}

Conflict of interest The authors declare that they have no conflict of interest.

Ethical approval This study was approved by the institutional ethics and animal welfare committee and the national authority (GZ 68.205/0196$\mathrm{WF} / \mathrm{V} / 3 \mathrm{~b} / 2016$ ).

Open Access This article is licensed under a Creative Commons Attribution 4.0 International License, which permits use, sharing, adaptation, distribution and reproduction in any medium or format, as long as you give appropriate credit to the original author(s) and the source, provide a link to the Creative Commons licence, and indicate if changes were made. The images or other third party material in this article are included in the article's Creative Commons licence, unless indicated otherwise in a credit line to the material. If material is not included in the article's Creative Commons licence and your intended use is not permitted by statutory regulation or exceeds the permitted use, you will need to obtain permission directly from the copyright holder. To view a copy of this licence, visit http://creativecommons.org/licenses/by/4.0/.

\section{References}

Baldi M, Hernández-Mora G, Jimenez C, Hutter SE, Alfaro A, Walzer C (2019) Leptospira seroprevalence detection and rabies virus absence in an urban raccoon (Procyon lotor) population in a highly populated area, Costa Rica. Vector Borne Zoonotic Dis 19:889-895. https:// doi.org/10.1089/vbz.2019.2444

Barton K (2019) MuMIn: Multi-model inference. R package version 1(43):6

Bates D, Mächler M, Bolker B, Walker S (2015) Fitting linear mixedeffects models using lme4. J Stat Softw 67:1-48. https://doi.org/10. 18637/jss.v067.i01

Battersby S, Hirschorn RB, Amman BR (2008) Commensal rodents. In: Bonnefoy X, Kampen H, Sweeney K (eds) Public health significance of urban pest. World Health Organization, Geneva, pp 387 419

Bjørnstad ON (2009) Ncf: spatial nonparametric covariance functions. R package version 1:2-8

Bjørnstad ON (2018) Epidemics. Models and data using R. Use R! Springer International Publishing, Cham

Boey K, Shiokawa K, Rajeev S (2019) Leptospira infection in rats: a literature review of global prevalence and distribution. PLoS Negl Trop Dis 13:e0007499

Bundesministerium für Digitalisierung und Wirtschaftsstandort (2019) Open Data Österreich. https://www.data.gv.at/. Accessed 24/04/ 2019

Burnham KP, Anderson DR (2002) Model selection and multimodel inference. A practical information-theoretic approach. Springer, New York. https://doi.org/10.1007/b97636

Byers KA, Cox SM, Lam R, Himsworth CG (2019) "They're always there": resident experiences of living with rats in a disadvantaged urban neighbourhood. BMC Public Health 19:853-853

Centers for Disease Control and Prevention (2006) Integrated pest management: conducting urban rodent surveys. US Department of Health and Human Services, Atlanta

Costa F et al (2015) Global morbidity and mortality of leptospirosis: a systematic review. PLoS Negl Trop Dis 9:e0003898 
Costa F, Porter FH, Rodrigues G, Farias H, de Faria MT, Wunder EA, Osikowicz LM, Kosoy MY, Reis MG, Ko AI, Childs JE (2014) Infections by Leptospira interrogans, Seoul virus, and Bartonella spp. among Norway rats (Rattus norvegicus) from the urban slum environment in Brazil. Vector Borne Zoonotic Dis 14:33-40

Dixon MA, Dar OA, Heymann DL (2014) Emerging infectious diseases: opportunities at the human-animal-environment interface. Vet Rec 174:546-551

Dupouey J, Faucher B, Edouard S, Richet H, Kodjo A, Drancourt M, Davoust B (2014) Human leptospirosis: An emerging risk in Europe? Comp Immunol Microbiol Infect Dis 37:77-83

Easterbrook J, Kaplan JB, Vanasco NB, Reeves WK, Purcell RH, Kosoy MY, Glass GE, Watson J, Klein SL (2007) A survey of zoonotic pathogens carried by Norway rats in Baltimore, Maryland, USA. Epidemiol Infect 135:1192-1199

Edgar RC (2010) Search and clustering orders of magnitude faster than BLAST. Bioinformatics 26:2460-2461

European Centre for Disease Prevention and Control (2014) Leptospirosis - Annual epidemiological report 2016 (2014 data). https://ecdc.europa.eu/en/publications-data/leptospirosis-annualepidemiological-report-2016-2014-data. Accessed 27/08/2019

European Centre for Disease Prevention and Control (2018) Leptospirosis - Annual epidemiological report for 2015. ECDC, Stockholm

Evangelista KV, Coburn J (2010) Leptospira as an emerging pathogen: a review of its biology, pathogenesis and host immune responses. Future Microbiol 5:1413-1425

Feng AYT, Himsworth CG (2014) The secret life of the city rat: a review of the ecology of urban Norway and black rats (Rattus norvegicus and Rattus rattus). Urban Ecosyst 17:149-162

Gardner-Santana LC, Norris DE, Fornadel CM, Hinson ER, Klein SL, Glass GE (2009) Commensal ecology, urban landscapes, and their influence on the genetic characteristics of city-dwelling Norway rats (Rattus norvegicus). Mol Ecol 18:2766-2778

Glass GE, Childs JE, Korch GW, LeDuc JW (1988) Association of intraspecific wounding with hantaviral infection in wild rats (Rattus norvegicus). Epidemiol Infect 101:459-472

Goarant C (2016) Leptospirosis: risk factors and management challenges in developing countries. Research and Reports in Tropical Medicine 7:49-62

Haake DA, Levett PN (2015) Leptospirosis in humans. Curr Top Microbiol Immunol 387:65-97

Hall TA (1999) BioEdit: a user-friendly biological sequence alignment editor and analysis program for windows 95/98/NT. Nucleic Acids Symp Ser 41:95-98

Hassell JM, Begon M, Ward MJ, Fèvre EM (2017) Urbanization and disease emergence: dynamics at the wildlife-livestock-human interface. Trends Ecol Evol 32:55-67

Heiberg A-C, Sluydts V, Leirs H (2012) Uncovering the secret lives of sewer rats (Rattus norvegicus): movements, distribution and population dynamics revealed by a capture-mark-recapture study. Wildl Res 39:202-219

Himsworth CG et al (2013a) Ecology of Leptospira interrogans in Norway rats (Rattus norvegicus) in an inner-city neighborhood of Vancouver, Canada. PLoS Negl Trop Dis 7:e2270

Himsworth CG, Parsons KL, Jardine C, Patrick DM (2013b) Rats, cities, people, and pathogens: a systematic review and narrative synthesis of literature regarding the ecology of rat-associated zoonoses in urban centers. Vector Borne Zoonotic Dis 13:349-359

Jansen A, Luge E, Guerra B, Wittschen P, Gruber AD, Loddenkemper C, Schneider T, Lierz M, Ehlert D, Appel B, Stark K, Nöckler K (2007) Leptospirosis in urban wild boars, Berlin, Germany. Emerg Infect Dis 13:739-742

Koizumi N, Muto M, Tanikawa T, Mizutani H, Sohmura Y, Hayashi E, Akao N, Hoshino M, Kawabata H, Watanabe H (2009) Human leptospirosis cases and the prevalence of rats harbouring
Leptospira interrogans in urban areas of Tokyo, Japan. J Med Microbiol 58:1227-1230

Krojgaard LH, Villumsen S, Markussen MDK, Jensen JS, Leirs H, Heiberg AC (2009) High prevalence of Leptospira spp. in sewer rats (Rattus norvegicus). Epidemiol Infect 27:1-7

Lau C (2010) Climate change, flooding, urbanisation and leptospirosis: fuelling the fire? Trans R Soc Trop Med Hyg 104:631-638

Lee MJ, Byers KA, Donovan CM, Bidulka JJ, Stephen C, Patrick DM, Himsworth C (2018) Effects of culling on Leptospira interrogans carriage by rats. Emerg Infect Dis 24:356-360

Mackenstedt U, Jenkins D, Romig T (2015) The role of wildlife in the transmission of parasitic zoonoses in peri-urban and urban areas. Int J Parasitol Parasites Wildl 4:71-79

McKinney ML (2006) Urbanization as a major cause of biotic homogenization. Biol Conserv 127:247-260

Mérien F, Amouriaux P, Pérolat P, Baranton G, Saint-Girons I (1992) Polymerase chain reaction for detection of Leptospira spp. in clinical sample. J Clin Microbiol 30:2219-2224

Minter A, Diggle PJ, Costa F, Childs J, Ko AI, Begon M (2017) Evidence of multiple intraspecific transmission routes for Leptospira acquisition in Norway rats (Rattus norvegicus). Epidemiol Infect 145: 3438-3448

Minter A, Diggle PJ, Costa F, Childs J, Ko AI, Begon M (2018) A model for leptospire dynamics and control in the Norway rat (Rattus norvegicus) the reservoir host in urban slum environments. Epidemics 25:26-34

Minter A, Himsworth CG, Byers KA, Childs JE, Ko AI, Costa F (2019) Tails of two cities: age and wounding are associated with carriage of Leptospira interrogans by Norway rats (Rattus norvegicus) in ecologically distinct urban environments. Front Ecol Evol 7:14

Moseley M, Rahelinirina S, Rajerison M, Garin B, Piertney S, Telfer S (2018) Mixed Leptospira infections in a diverse reservoir host community, Madagascar, 2013-2015. Emerg Infect Dis 24:1138-1140

NCBI Resource Coordinators (2017) Database resources of the National Center for biotechnology information. Nucleic Acids Res 46:D8 D13

Nelson L, Clark FW (1973) Correction for sprung traps in catch/effort calculations of trapping results. J Mammal 54:295-298

Pellizzaro M et al (2019) Molecular detection of Leptospira spp. in rats as early spatial predictor for human disease in an endemic urban area. PLoS One 14:e0216830-e0216830

Pijnacker R et al (2017) Marked increase in leptospirosis infections in humans and dogs in the Netherlands, 2014. Eurosurveillance 21: 30211

Poeppl W et al (2013) High prevalence of antibodies against Leptospira spp. in male Austrian adults: a cross-sectional survey, April to June 2009. Eurosurveillance 18:20509

Robins JH, Hingston M, Matisoo-Smith E, Ross HA (2007) Identifying Rattus species using mitochondrial DNA. Mol Ecol Notes 7:717729

Rohland N, Reich D (2012) Cost-effective, high-throughput DNA sequencing libraries for multiplexed target capture. Genome Res 22: 939-946

Sato Y, Mizuyama M, Sato M, Minamoto T, Kimura R, Toma C (2019) Environmental DNA metabarcoding to detect pathogenic Leptospira and associated organisms in leptospirosis-endemic areas of Japan. Sci Rep 9:6575

Socolovschi C, Angelakis E, Renvoisé A, Fournier PE, Marié JL, Davoust B, Stein A, Raoult D (2011) Strikes, flooding, rats, and leptospirosis in Marseille, France. Int J Infect Dis 15:e710-e715

Strand TM, Löhmus M, Persson Vinnersten T, Råsbäck T, Sundström K, Bergström T, Lundkvist Å (2015) Highly pathogenic Leptospira found in urban brown rats (Rattus norvegicus) in the largest cities of Sweden. Vector Borne Zoonotic Dis 15:779-781 
Strand TM, Lundkvist $\AA$ (2019) Rat-borne diseases at the horizon. A systematic review on infectious agents carried by rats in Europe 1995-2016. Infect Ecol Epidemiol 9:1553461-1553461

Sunnucks P, Hales DF (1996) Numerous transposed sequences of mitochondrial cytochrome oxidase I-II in aphids of the genus Sitobion (Hemiptera: Aphididae). Mol Biol Evol 13:510-524

Thibeaux R et al (2017) Seeking the environmental source of leptospirosis reveals durable bacterial viability in river soils. PLoS Negl Trop Dis 11:e0005414

Thibeaux R et al (2018) Deciphering the unexplored Leptospira diversity from soils uncovers genomic evolution to virulence. Microb Genom 4:e000144

United Nations (2016) Composition of macro geographical (continental) regions, geographical sub-regions, and selected economic and other groupings. United Nations. https://unstats.un.org/unsd/methods/ m49/m49regin.htm\#developed. Accessed 21/02/2017

United Nations Department of Economic and Social Affairs Population Division (2019) World Urbanization Prospects: The 2018 Revision (ST/ESA/SER.A/420). United Nations, New York
Vadell MV, Cavia R, Suárez OV (2010) Abundance, age structure and reproductive patterns of Rattus norvegicus and Mus musculus in two areas of the city of Buenos Aires. Int J Pest Manage 56:327-336

Vincent AT et al (2019) Revisiting the taxonomy and evolution of pathogenicity of the genus Leptospira through the prism of genomics. PLoS Negl Trop Dis 13:e0007270

Vinetz JM, Glass GE, Flexner CE, Mueller P, Kaslow DC (1996) Sporadic urban leptospirosis. Ann Intern Med 125:794-798

Vitale M, Agnello S, Chetta M, Amato B, Vitale G, Bella CD, Vicari D, Presti VDML (2018) Human leptospirosis cases in Palermo Italy. Role Rodents Climate J Infection Public Health 11:209-214

Yusof MA, Mohd-Taib FS, Ishak SN, Md-Nor S, Md-Sah SA, Mohamed NZ, Azhari NN, Neela V, Sekawi Z (2019) Microhabitat factors influenced the prevalence of pathogenic Leptospira spp. in small mammal host. EcoHealth 16:260-274

Zahner GE, Kasl SV, White M, Will JC (1985) Psychological consequences of infestation of the dwelling unit. Am J Public Health 75:1303-1307

Zilber A-L, Belli P, Artois M, Kodjo A, Djelouadji Z (2016) First observation of Leptospira interrogans in the lungs of Rattus norvegicus. Biomed Res Int 2016:9656274 